\title{
Análise das condições de permanência do estudante com deficiência na Educação Superior
}

\author{
Alexandra Ayach Anache \\ Universidade Federal de Mato Grosso do Sul - Campo Grande - MS - Brasil \\ Lysa Duarte Cavalcante \\ Universidade Federal de Mato Grosso do Sul - Campo Grande - MS - Brasil
}

\begin{abstract}
Resumo
Considerando que nos últimos quinze anos houve a ampliação do acesso de estudantes com deficiência na educação superior, torna-se necessário que se efetivem políticas institucionais que visem promover a acessibilidade. O objetivo deste trabalho foi analisar as condições de permanência de acadêmicos com deficiência, em cursos de educação superior de uma instituição federal. A metodologia empregada foi de natureza exploratória, aproximando-se da técnica de estudo de caso. Os procedimentos adotados previram a análise dos conteúdos dos documentos institucionais e a realização de entrevistas semiestruturadas. A pesquisa foi desenvolvida em uma universidade pública, coma participação de 11 acadêmicos com deficiência e 11 diretores de unidades. A análise dos conteúdos das informações coletadas permite concluir que, conquanto se tenham alcançado alguns avanços para tornar a universidade mais acessível aos estudantes, ainda se evidencia a necessidade de investimentos em infraestrutura, em mudança de concepção do currículo, na formação dos professores e demais profissionais, na produção e veiculação de informações para disseminar a cultura da educação inclusiva, de modo a tornarem viáveis as condições para que os estudantes com deficiência concluam com êxito os seus cursos de educação superior.
\end{abstract}

Palavras-chave: Educação Superior; Educação Inclusiva; evasão escolar.

\section{Analysis the conditions of the permanence of academics with disabilities in higher education}

\begin{abstract}
Considering that in the last fifteen years there has been an increase in the access of students with disabilities to higher education, it is necessary to implement institutional policies aimed at promoting accessibility. The objective of this study was to analyze the conditions of the permanence of academics with disabilities in higher education courses of a federal institution. The methodology used was exploratory in nature, approaching the case study technique. The procedures adopted foreseen the analysis of the contents of the institutional documents and the accomplishment of semistructured interviews. The research was developed in a public university, with the participation of 11 academics with disabilities and 11 directors of units. The analysis of the contents of the collected information allows to conclude that, although some advances have been made to make the university more accessible to the students, it is still evident the need of investments in infrastructure, in change of curriculum conception, in the training of teachers and other professionals, in the production and dissemination of information to disseminate the culture of inclusive education, so as to make feasible the conditions for students with disabilities to successfully complete their higher education courses.
\end{abstract}

Keywords: Higher Education; Inclusive Education; school dropouts.

\section{Análisis de las condiciones de permanencia del estudiante con discapacidad en la educación universitaria}

\begin{abstract}
Resumen
Considerando que en los últimos quince años hubo la expansión del acceso de estudiantes con discapacidad en la educación universitaria, se vuelve necesario que se efectivice políticas institucionales que persigan promover la accesibilidad. El objetivo de este estudio fue analizar las condiciones de permanencia de académicos con discapacidad, en cursos de educación universitaria de una institución federal. Se empleó la metodología de naturaleza exploratoria, acercándose de la técnica de estudio de caso. Los procedimientos adoptados previeron el análisis de los contenidos de los documentos institucionales y la realización de entrevistas semiestructuradas. Se desarrolló la investigación en una universidad pública, con la participación de 11 académicos con discapacidad y 11 directores de unidades. El análisis de los contenidos de las informaciones recolectadas permite concluir que, aunque se tengan alcanzado algunos avances para volver la universidad más accesible a los estudiantes, aun se evidencia la necesidad de inversiones en infraestructura, en cambios de concepción del currículo, en la formación de los profesores y demás profesionales, en la producción y vinculación de informaciones para diseminar la cultura de la educación inclusiva, de modo a volver viables las condiciones para que los estudiantes con discapacidad concluyan con éxito sus cursos de educación universitaria.
\end{abstract}

Palabras clave: Educación Universitaria; Educación Inclusiva; evasión escolar. 


\section{Introdução}

Este trabalho apresenta o resultado de estudos sobre as condições de permanência de estudantes que apresentam deficiência, na educação superior. As pessoas com deficiência são aquelas que possuem "impedimentos de longo prazo de natureza física, mental, intelectual ou sensorial, os quais, em interação com diversas barreiras, podem obstruir sua participação plena e efetiva na sociedade em igualdades de condições com as demais pessoas"(Lei $n^{\circ} 13.146$, 2015 p.1).

A inclusão na educação superior integra o conjunto das políticas educacionais, dentre elas a Política de Cotas, instituída pelo Decreto 12.711 de 29 de agosto de 2012, que pretende democratizar o acesso de pessoas que, por questões étnicas, de classes sociais desfavorecidas e com deficiência encontram mais dificuldade para entrar e permanecer em uma universidade pública; confira-se o Art. $3^{\circ}$ desse documento legal:

Art. 3o: Em cada instituição federal de ensino superior, as vagas de que trata o art. 1ㅇdesta Lei serão preenchidas, por curso e turno, por autodeclarados pretos, pardos e indígenas e por pessoas com deficiência, nos termos da legislação, em proporção ao total de vagas no mínimo igual à proporção respectiva de pretos, pardos, indígenas e pessoas com deficiência na população da unidade da Federação onde está instalada a instituição, segundo o último censo da Fundação Instituto Brasileiro de Geografia e Estatística - IBGE.

Nos últimos anos houve um crescimento de $590,78 \%$ do número de estudantes que ingressou na educação superior (Inep, 2014), com prevalência de matrículas nas instituições de ensino da iniciativa privada, mediante as bolsas concedidas pelo Fundo de Financiamento Estudantil $\left(\right.$ FIES) ${ }^{1}$ e Programa Universidade para todos (PROUNI) ${ }^{2}$. Nas universidades públicas (estaduais e federais) esse número tende a crescer, tendo em vista as atuais políticas de ação afirmativa, a exemplo das reservas de vagas. Santana (2016) informa que esse número aumentou nas instituições federais, haja vista que, de 6.739 .689 estudantes matriculados em cursos de graduação no ensino superior, 1.032 .936 estão nessas instituições. Em 2015 foram registradas 33.377 matrículas do público alvo da educação especial (Cabral, 2017). Estima-se que esse número cresça com a implantação da reserva na educação superior pelo Decreto 9.034, de 20 de abril de 2017.

1 O FIES foi criado pelo Ministério da Educação, é voltado especificamente para o financiamento dos estudos para alunos que escolheram instituições particulares.

2 O PROUNI foi criado para promover a acessibilidade à educação para quem tem renda baixa. Por meio dele, é possível conseguir bolsas integrais ou parciais para universidades ou faculdades particulares cadastradas no programa em todo o país.
As discussões em torno do público alvo da educação especial ainda é polêmica, pois há uma corrente que defende que os atendimentos dos núcleos de acessibilidade sejam restritos aos estudantes que apresentam "deficiência, transtorno globais do desenvolvimento e com altas habilidades e superdotação" (Brasil, 2011, p.1) e outra que propõe a ampliação do acesso aos que apresentam transtornos mentais, pelo fato de eles também necessitarem de serviços especiais (Cabral, 2017).

O público alvo das pesquisas brasileiras voltadas à acessibilidade, na educação, em sua maioria, é de estudantes que apresentam deficiência física (Cambruzzi, Costa, \& Denari, 2013) e sensorial (visual e auditiva) (Lima, 2012), (Bisol, Valentini, \& Simoni, 2010), (Siqueira \& Santana, 2010), (Pereira, Santos, \& Silva, 2011), (Nogueira, 2012), (Camargo, 2012), (Siqueira \& Aquillera, 2015), (Brito \& Zeppone, 2013), (Reis, 2010), (Rossetto, 2009), (Marques \& Gomes, 2014), (Moreira, Michels, \& Colossi, 2006), entre outros.

A Secretaria de Educação Continuada e Alfabetização, Diversidade e Inclusão (SECADI) e a Secretaria de Ensino Superior (SESU), desde 2005, propuseram o Programa Incluir, com o objetivo de oferecer recursos financeiros que proporcionem condições de permanência de estudantes com deficiência nas instituições federais de educação superior, quais sejam a adequação arquitetônica, a aquisição de recursos de tecnologia assistiva, mobiliários, material pedagógico acessível, fomentando, dessa forma, a implantação dos núcleos de acessibilidade ou órgãos similares para assumirem, juntamente com os outros setores das instituições, ações que visem ao sucesso acadêmico desses indivíduos.

Em 2013 estavam previstos no orçamento da União 11 milhões de reais para serem destinados às universidades federais com vistas à adequação de seus espaços físicos e para aquisição de recursos didáticos e tecnologia assistiva, por meio do Programa Incluir. O valor destinado a cada uma delas foi proporcional ao número total de estudantes matriculados em seus cursos (Brasil, 2013).

Embora haja movimentos tanto no âmbito internacional quanto nacional para que o acesso, a permanência e o acompanhamento na educação superior sejam institucionalizados, ainda são encontradas dificuldades para efetivá-las no âmbito das universidades públicas, com destaque para as barreiras no âmbito do currículo, a falta de recursos acessíveis e formação profissional docente e dos técnicos administrativos para lidarem com os estudantes com deficiências. Portanto, as condições de permanência ainda ficam restritas aos esforços individuais, de familiares e colegas, conforme informaram Alcoba (2008), Maiola, Boos e Fischer (2008), Moreira (2011), Anache, Rovetto e Oliveira (2014) e Cabral (2017).

Rosseto (2005), Moreira, Bolsanello e Seger (2011), Anache, Rovetto e Oliveira (2014) adensaram essas conclusões, afirmando que será necessário avançar na construção de políticas institucionais que superem as barreiras burocráticas e criem estratégias educacionais no interior dos cursos de graduação na perspectiva da inclusão. Sobre isso, 
o Relatório Executivo: Seminário Local de "Acessibilidade e Inclusão na Unifesp: Unifesp para Todos", realizado nos dias 16 e 17 de junho, reafirmou essas conclusões.

O Decreto $n^{\circ} 6.571 / 08$ (2008), que define o atendimento educacional especializado (AEE) como um sistema de apoio à escolarização de estudantes com Necessidades Educacionais Especiais (NEE), assegura que, na educação superior, as ações devem ocorrer no âmbito dos núcleos de acessibilidade e

envolvem o planejamento e a organização de recursos e serviços para a promoção da acessibilidade arquitetônica, nas comunicações, nos sistemas de informação, nos materiais didáticos e pedagógicos, que devem ser disponibilizados nos processos seletivos e no desenvolvimento de todas as atividades que envolvam o ensino, a pesquisa e a extensão (Decreto $n^{\circ} 6.571 / 08,2008$, Art. $3^{\circ}, \S 3^{\circ}$ ).

As características individuais do estudante com deficiência, bem como as especificidades dos cursos de graduação e pós-graduação, tornam complexas as atividades dos núcleos de acessibilidade, pois requerem a articulação de ações coletivas e, ao mesmo tempo, particulares, para cada área de conhecimento, as quais devem estar previstas no Plano de Desenvolvimento Institucional.

Nesse sentido, além da infraestrutura arquitetônica e recursos materiais acessíveis é indispensável que se invista na formação dos profissionais, considerando que as necessidades educacionais específicas de cada estudante se manifestarão no encontro e confronto com as características do curso escolhido por ele. Isso exigirá que o desenho curricular contemple as possibilidades de adequações e diferenciações das propostas pedagógicas ofertadas no âmbito das universidades.

O objetivo principal deste estudo ${ }^{3}$ foi analisar as condições de permanência do acadêmico com deficiência em cursos de educação superior de uma instituição federal.

\section{Método}

Trata-se de um estudo exploratório de caráter analítico descritivo que visa obter informações sobre as ações de permanência dos estudantes com deficiência que ingressaram em uma universidade pública. Por se tratar de uma situação particular, ela se aproxima da técnica de estudo de caso. André (2013, p. 98), ao estudar autores que fazem o uso dessa técnica afirma que

há dois traços comuns: a) o caso tem uma particularidade que merece ser investigada; e b) o estudo deve considerar a multiplicidade de aspectos que caracteriza o caso, o que vai requerer o uso de múltiplos procedimentos metodológicos para desenvolver um estudo em profundidade.

3 Este estudo foi aprovado pelo Comitê de Ética, Número do Parecer: 1.840 .736
A pesquisa foi desenvolvida em uma universidade pública do estado de Mato Grosso do Sul, que possui 10 campi distribuídos no interior do estado e a cidade universitária situada em Campo Grande. Essa instituição possui 16 mil estudantes e 16 unidades (10 faculdades, cinco institutos e uma Escola) que oferecem cursos de graduação e programas de pós- graduação, tanto na modalidade presencial quanto à distância.

O processo de seleção dos participantes desta pesquisa constituiu uma das dificuldades enfrentadas, pois foram feitas seis tentativas de contato por meio telefônico com 165 estudantes, em períodos variados. Quarenta acadêmicos não atenderam às ligações. Dos 125 com quem se estabeleceu contato, quinze deles não apresentam deficiência e desistiram de seus cursos. Dos 110 estudantes que atenderam às ligações, 99 preferiram não responder às nossas perguntas, o que provocou uma discrepância em relação à confirmação dos dados fornecidos na matrícula. Desse conjunto, onze aceitaram participar da pesquisa, e já integravam o conjunto dos acadêmicos que haviam sido atendidos pelo setor de acessibilidade. Registre-se que, na ocasião da pesquisa, estavam sem processo de atendimento 23 estudantes.

Desse modo, participaram desse estudo onze (11) acadêmicos com deficiências (Quadro 1), sendo três do sexo feminino e oito do sexo masculino, e onze (11) diretores de unidades, dois do sexo feminino e nove do sexo masculino, identificados com os números $1,2,3,4,5,6,7,8,9$, 10, 11. Ao longo deste trabalho serão utilizadas as siglas Ac. para acadêmicos e $D$ para diretores de unidade, conforme indicado no Quadro 1.

Como se pode constatar, dos 11Ac. com deficiência que concordaram em participar da pesquisa, cinco apresentaram deficiência auditiva, quatro têm deficiência visual e dois apresentam deficiência física. A faixa etária desses acadêmicos varia entre 18 e 60 anos de idade.

A deficiência auditiva declarada pelos informantes refere-se à perda parcial ou total da capacidade de detectar sons, que pode ser decorrente de má-formação (causa genética), lesão na orelha ou na composição do aparelho auditivo. A Surdez se caracteriza pela impossibilidade total de escutar qualquer tipo de som. De acordo com o parágrafo $2^{\circ}$ do Decreto 5.626, de 22 de dezembro de 2005, que regulamenta a Lei $n^{\circ} 10.436$, de 24 de abril de 2002 e dispõe sobre a Língua Brasileira de Sinais-Libras, e o art. 18 da Lei $\mathrm{n}^{\circ} 10.098$, de 19 de dezembro de 2000, "considera-se pessoa surda aquela que, por ter perda auditiva, compreende e interage com o mundo por meio de experiências visuais, manifestando sua cultura principalmente pelo uso da Língua Brasileira de Sinais - Libras". No parágrafo único desse mesmo Decreto, a deficiência auditiva é compreendida como "perda bilateral, parcial ou total, de quarenta e um decibéis (dB) ou mais, aferida por audiograma nas frequências de $500 \mathrm{~Hz}, 1.000 \mathrm{~Hz}, 2.000 \mathrm{~Hz}$ e $3.000 \mathrm{~Hz}$.

Dentre os tipos de deficiência auditiva estão: a condutiva, mista, neurossensorial e central. A primeira acontece quando há problemas na condução do som desde o conduto 
Quadro 1. Identificação dos participantes da pesquisa (2015).

\begin{tabular}{|c|c|c|c|c|c|}
\hline Acadêmico (a) & Gênero & Idade & Estado civil & Tipo de deficiência & Curso de graduação \\
\hline 1 & Masculino & 31 anos & Casado (a) & $\begin{array}{l}\text { Deficiência Visual (baixa } \\
\text { visão) }\end{array}$ & Eletrotécnica industrial \\
\hline 2 & Masculino & 32 anos & Solteiro (a) & Deficiência Física & Tecnólogo \\
\hline 3 & Masculino & 60 anos & Casado (a) & Deficiência Auditiva & $\begin{array}{l}\text { Técnico de processos } \\
\text { gerenciais }\end{array}$ \\
\hline 4 & Masculino & 46 anos & Solteiro (a) & $\begin{array}{l}\text { Deficiência Visual (baixa } \\
\text { visão) }\end{array}$ & Ciências Sociais \\
\hline 5 & Feminino & 18 anos & Solteiro (a) & Deficiência Auditiva & $\begin{array}{l}\text { Engenharia de } \\
\text { Computação }\end{array}$ \\
\hline 6 & Feminino & 39 anos & Solteiro (a) & $\begin{array}{l}\text { Deficiência Auditiva } \\
\text { (perda auditiva unilateral) }\end{array}$ & Administração \\
\hline 7 & Masculino & 44 anos & Casado (a) & $\begin{array}{l}\text { Deficiência Auditiva } \\
\text { (neurossensorial } \\
\text { bilateral) }\end{array}$ & Ciências Contábeis \\
\hline 8 & Masculino & 19 anos & Solteiro (a) & $\begin{array}{l}\text { Deficiência Visual (baixa } \\
\text { visão) }\end{array}$ & Jornalismo \\
\hline 9 & Masculino & 34 anos & Casado (a) & $\begin{array}{l}\text { Deficiência Visual (baixa } \\
\text { visão) }\end{array}$ & Química \\
\hline 10. & Masculino & 37 anos & Casado (a) & Deficiência física & Ciências Contábeis \\
\hline 11. & Feminino & 22 anos & Solteiro (a) & Deficiência Auditiva & Ciências Econômicas \\
\hline
\end{tabular}

Fonte: Elaborado pelas autoras.

auditivo externo até a orelha interna; na maioria dos casos ela pode ser corrigida por meio de cirurgia. A neurossensorial ocorre quando há uma impossibilidade de recepção por lesão na orelha interna ou no nervo auditivo. A deficiência mista é característica de quando as perdas condutivas e neurossensorial ocorrem em uma mesma pessoa. A deficiência auditiva central nem sempre é acompanhada de diminuição da sensitividade auditiva, mas manifesta-se por diferentes graus de dificuldade na compreensão das informações sonoras (Sistemas Conselhos Federal de Fonoaudiologia e de Regionais de Fonoaudiologia, 2013).

A deficiência visual pode ser classificada em cegueira e baixa visão. A primeira refere-se à ".... alteração grave ou total de uma ou mais das funções elementares da visão que afeta de modo irremediável a capacidade de perceber cor, tamanho, distância, forma, posição ou movimento em um campo mais ou menos abrangente" (Sá, Campos, \& Silva, 2007, p. 15).

Sá, Campos e Silva (2007) consideram que a baixa visão é um conceito complexo, pois refere-se à multiplicidade e à magnitude dos comprometimentos das funções visuais, pois essas variam desde a simples percepção de luz até à diminuição da acuidade e do campo de visão que interferem, limitando o desempenho de atividades do cotidiano.

De acordo com o Decreto ${ }^{\circ} 5.296$ de 2 de dezembro de 2004, a deficiência física está sendo compreendida como alteração completa ou parcial de uma ou mais partes do corpo humano, comprometendo a função física do indivíduo, a execução de suas atividades, limitando a sua autonomia.

Além dos estudantes com deficiências, participaram desta pesquisa onze diretores de unidades da cidade universitária, sendo que dez deles estão na gestão desde 2013 e apenas o D3 está no cargo desde 2009. As análises dos documentos institucionais, como o Plano de Desenvolvimento Institucional (2015 - 2019) e os relatórios disponibilizados no setor de acessibilidade da Universidade são necessários para a compreensão dos princípios e das propostas de ensino, pesquisa e extensão da Universidade, lócus desta pesquisa.

As entrevistas semiestruturadas com os participantes da pesquisa tiveram a duração de 40 minutos. Elas foram realizadas individualmente, sendo que os estudantes foram contatados via telefone e depois se apresentaram na sala do setor de acessibilidade da Instituição; os diretores das Unidades foram entrevistados em seus gabinetes. Os diálogos estabelecidos nessas entrevistas foram gravados e também registrados em um caderno de campo. Posteriormente, realizamos as transcrições e as análises de conteúdo das 22 entrevistas, considerando, também, os documentos já referidos.

A seguir, apresentamos as análises de forma integrada, relacionando os aspectos pertinentes ao público de estudantes com deficiências e as condições de permanência para que esses acadêmicos concluam seus cursos com êxito. 


\section{Resultados e discussões}

A preocupação em relação às condições de acesso das pessoas com deficiências aos cursos da Universidade pesquisada é recente. As normativas garantem a esses acadêmicos alguns recursos de tecnologia assistiva, profissionais de apoio e, também, um tempo mais extenso para realização das provas, independentemente do sistema de seleção que as unidades adotam - Sistema de Seleção Unificada, Programa de Avaliação Seriada, Vestibular ou mesmo misto.

Até 2016 ingressava-se (no início e no meio do ano) nos cursos da Universidade lócus da pesquisa pelo Sistema de Seleção Unificada - Sisu, que visa selecionar os candidatos às vagas das instituições públicas da educação superior que utilizam a nota do Exame Nacional do Ensino Médio (Enem). As condições de acesso aos acadêmicos com deficiências são definidas por ações que visam disponibilizar recursos como Tradutor Intérprete de Língua Brasileira de Sinais (Libras), computadores com sistema de comunicação para cegos entre outros que atendam às necessidades educacionais desses estudantes.

A Lei Brasileira de Inclusão (Lei no 13.146, 2015) determina que para os processos seletivos de acesso ao ensino é necessário que se disponibilizem os "recursos de acessibilidade e de tecnologia assistiva adequados, previamente solicitados e escolhidos pelo candidato com deficiência" (Lei n 13.146, 2015).

Desde 2013, com a implantação do Setor de Acessibilidade na Universidade pesquisada, há um esforço por parte dos profissionais dessa Unidade em identificar os acadêmicos com deficiências, matriculados nessa Instituição. Assim, a cada início de semestre é realizado o levantamento dos estudantes que declararam possuir deficiências, visando atender às necessidades educacionais específicas desses estudantes.
No relatório do setor de acessibilidade $(2016)^{4}$ identificaram-se 155 acadêmicos matriculados que declararam ter algum tipo de deficiência, a saber: três acadêmicos com deficiência visual; 112 com baixa visão; seis surdos; 15 com deficiência auditiva e 19 acadêmicos com deficiência física.

Os números de estudantes com baixa visão são considerados alarmantes, levando à suspeita de que não têm compreensão do conceito sobre a baixa visão. Essa situação requer dos dirigentes da Universidade atenção para que seja reformulada a ficha de matrícula no Sistema Acadêmico, explicitando o conceito de cada deficiência. Também sugere-se que os funcionários e coordenadores observem as informações oferecidas pelos acadêmicos no ato da confirmação da matrícula. Conforme consta no Relatório Executivo: Seminário Local de Acessibilidade e Inclusão na Unifesp (2016), a identificação deste público foi alvo de discussão, pois, se por um lado há aqueles que se identificaram como deficientes visuais em decorrência da dificuldade de compreensão do conceito, por outro lado existem aqueles acadêmicos que preferiram não declarar a sua deficiência com receio de serem discriminados.

Ao confrontar os números de acadêmicos com deficiência com os três segmentos da Instituição, observa-se que não há consenso entre os dados oficiais obtidos pelo núcleo de informática, com os obtidos junto aos Diretores das unidades e com a coordenação do setor de acessibilidade da Instituição pesquisada. Ressalta-se, ainda, a presença de um estudante com deficiência intelectual ${ }^{5}$, conforme o demonstra o Quadro 2.

4 As referências do Relatório do setor de acessibilidade da Instituição serão omitidas, para garantir o sigilo da identidade da Instituição pesquisada.

5“ Deficiência intelectual é uma incapacidade caracterizada por limitações significativas tanto no funcionamento intelectual (raciocínio, aprendizado, resolução de problemas) quanto no

Quadro 2. Números de matrícula de acadêmicos por tipo de deficiência* (2015).

* Os conceitos de deficiência adotados neste trabalho podem ser obtidos no Portal do Inep. Disponível em: http://portal.inep. gov.br/web/educacenso/educacao-especial.

\begin{tabular}{ccccc}
\hline Tipo de deficiência & Dados oficiais & $\begin{array}{c}\text { Dados informados } \\
\text { pelos diretores }\end{array}$ & $\begin{array}{c}\text { Dados informados pelo } \\
\text { setor de acessibilidade }\end{array}$ & Total \\
\hline Deficiência Visual & 3 & 1 & 4 & 1 \\
\hline Baixa Visão & 112 & 1 & 2 & 21 \\
\hline Deficiência Física & 19 & 0 & 4 & 15 \\
\hline Deficiência Auditiva & 15 & 0 & 0 & 6 \\
\hline Surdez & 6 & 1 & 0 & 1 \\
\hline Deficiência & 0 & 1 & & 15 \\
\hline
\end{tabular}

Fonte: Setor de Acessibilidade/Núcleo de informática/Diretores das Unidades da cidade universitária. 
O dissenso entre os diferentes setores da Instituição aponta para a necessidade de se melhorar o processo de identificação dos acadêmicos com deficiência, no ato da confirmação da matrícula, visando à construção de um sistema integrado de informações que proporcione condições para promover ações que fortaleçam o sucesso acadêmico daqueles que ingressaram nos cursos, conforme está previsto no PDI (2015-2019).

Compreende-se que o sucesso é um conceito que envolve fatores quantitativos e qualitativos. Os primeiros referem-se ao desempenho acadêmico, conclusão do curso e envolvimento dos estudantes em atividades de ensino, pesquisa e extensão; somam-se a esses, os fatores qualitativos relacionados à aprendizagem, que se expressam na transformação do estudante (Harvey \& Williams, 2010).

Há outros condicionantes implicados para que o acadêmico com deficiência consiga concluir seu curso na educação superior, como o fator socioeconômico, haja vista que a maioria da população que tem essa característica possui condições financeiras precárias, conforme os dados censitários de 2010 (Anache, 2015).

Entre os participantes da pesquisa, cinco são casados e informaram que precisavam trabalhar para prover o sustento de suas famílias, pois possuem cônjuges e filhos, e também revelaram dificuldades financeiras para proverem sozinhos esse sustento. Essa condição econômica também é apresentada pelos cinco acadêmicos solteiros. Apenas o Ac. 5 possui situação socioeconômica confortável, não necessitando de trabalhar para prover o seu sustento.

Além disso, a faixa etária dos estudantes foi um aspecto que chamou atenção, pelo fato de serem, em sua maioria, adultos acima dos 22 anos, e estavam fazendo o curso superior mediante a ampliação da oferta de vagas e de cursos disponibilizados pela Universidade. O Ac 2 informou que o curso de Tecnologia era a segunda graduação que realizava, pois é engenheiro e quis complementar o seu currículo.

A escolha dos cursos foi um aspecto também observado, pois constatou-se o interesse variado em relação aos cursos das áreas de humanas - ciências sociais, jornalismo e ciências econômicas, administração e ciências contábeis. Além desses, a opção pelos cursos da área de ciências exatas e tecnológicas foi recorrente entre os participantes deste estudo (seis acadêmicos optaram por cursos de ciências exatas e tecnológicas e cinco acadêmicos pela área de ciências humanas). A diversificação de cursos proporciona aos estudantes maiores possibilidades de escolhas, como afirmam Rocha e Miranda (2009),

A ampliação do acesso mediante as políticas nacionais se pauta no princípio da inclusão, exige dos espaços educacionais infraestrutura adequada, currículos e informações acessíveis, além de investimentos na formação dos profissionais da instituição, favorecendo, dessa forma, condições de permanência e viabilizando o sucesso acadêmico dos estudantes com deficiência.

comportamento adaptativo, que cobre uma gama de habilidades sociais e práticas do dia a dia. Esta deficiência se origina antes da idade de 18 anos" (Shogren \& cols., 2010, p. 6).

\section{As Condições de Permanência dos acadêmicos com deficiência}

Para que o estudante com deficiência conclua seu curso na universidade é necessário que ele possua condições de acesso ao currículo, às informações que circulam no meio acadêmico, à tecnologia e aos recursos humanos capacitados. Esses aspectos serão viabilizados se rompermos as barreiras atitudinais, as quais extrapolam o âmbito do assegurado nas normativas legais. Trata-se de questões mais complexas, do âmbito da cultura, dos valores meritórios cristalizados na história de cada instituição.

No que se refere à infraestrutura, todos os participantes deste estudo informaram que as condições de acessibilidade tanto em ambientes externos quanto internos são precárias, requerendo maiores investimentos. Este aspecto está previsto no PDI 2015 - 2019 da Instituição pesquisada ${ }^{6}$. Esse documento registra as informações sobre a existência de um laboratório de educação especial na cidade universitária e nas demais unidades: 37 pisos táteis, 24 elevadores, 192 banheiros adaptados e 93 rampas de acesso e reformas dos prédios antigos.

No aprofundamento das questões relacionadas à infraestrutura, os participantes da pesquisa afirmaram que os pisos do corredor central, assim como vários lugares dos pátios da Instituição são perigosos para todos, inclusive para as pessoas que possuem mobilidade reduzida. O Ac. 2 afirma: "Eu não tenho dificuldade com as matérias, o problema é a locomoção mesmo, o restante é fácil comparado às rampas que não estão lá quando você precisa delas". A queixa em relação à adequação do espaço físico, tanto nos ambientes internos quanto nos externos, tem sido constante por parte dos acadêmicos e dos diretores das unidades. $O$ relato de D3 ilustra essa afirmação:

Os blocos dos centros sofrem com algumas áreas que são mais velhas, pois não tem como mudar uma estrutura inteira para acrescentar mais rampas ou mais espaços, como em salas de aulas, algumas são muito pequenas para proporcionar a reforma completa e isso prejudica um cadeirante, por exemplo.

A situação de incapacidade dos participantes desta pesquisa se agudiza em decorrência das dificuldades de mobilidade no campus da Instituição, revelando o impacto do processo de sucateamento das universidades públicas brasileiras, a partir dos anos 1990, ocasionado pela diminuição dos investimentos públicos em educação, seja em infraestrutura ou no quadro de pessoal. De outro modo, nem sempre os recursos são alocados considerando as necessidades das pessoas que apresentam deficiências, aspecto que requer aprofundamento nas pesquisas. O desenho institucional é uma linguagem potente e expressa a cultura do local.

A inacessibilidade e a manutenção das construções antigas são alvos de reclamações dos participantes da

6 Todos os documentos da Instituição pesquisada serão mantidos sob sigilo, conforme o previsto no Termo Livre Esclarecido. 
pesquisa, mas também os prédios mais recentes apresentam problemas dessa natureza. Vale registrar que a instituição está investindo na construção de rotas acessíveis para ligar uma unidade à outra; no entanto, ainda é insuficiente, em decorrência da falta de verbas para essa finalidade.

A adequação dos banheiros, rampas de acesso nos ambientes e os elevadores não recebem manutenção com frequência, dificultando o uso seguro desses locais por parte dos estudantes com deficiências físicas ou com mobilidade reduzida. Não são raros os casos de desistências dos cursos em decorrência da precariedade das condições físicas dos prédios, conforme ratificado na fala do participante D 10:

No bloco principal a rampa que tem a inclinação é muito alta e sua curva fechada, como um cadeirante pode passar por ela? Já teve um cadeirante que parou de frequentar a universidade porque era uma dificuldade chegar até a sala de aula.

Destaca-se, também, a questão da adequação dos laboratórios de ensino, pois a maioria não é acessível e não possuí recursos adaptados para viabilizar a aprendizagem de estudantes com deficiências. Esse aspecto foi ressaltado por todos os diretores, a exemplo do que afirmou o diretor D5:

Alguns laboratórios de práticas, mais antigos, não adequam um acadêmico cadeirante, por exemplo, as bancadas são altas demais e o espaço apertado. $O$ acadêmico com uma deficiência visual (cegueira) pode não se interessar por determinado curso por saber que terá de ir para um laboratório e não terá como realizar as práticas.

Problemas de adaptação de mobiliários e com equipamentos de áudio foram repetidamente apontados pelos estudantes com deficiência visual, conforme se evidencia no relato do entrevistado Ac. 03: "Por vezes não consigo escutar bem o que o professor fala nos ambientes mais afastados da sala de aula, eu preferiria que os professores utilizassem microfones, assim seria mais fácil o meu entendimento". Esse acadêmico afirma que esses materiais deveriam estar disponíveis em outros espaços da instituição, como laboratórios, bibliotecas e salas com tutores em todas as unidades. $\mathrm{Na}$ opinião dos diretores, essas condições seriam, sim, ideais.

Os recursos de tecnologia assistiva ${ }^{7}$, como cadeira de rodas e andadores, carteira e cadeiras adaptadas; recursos de comunicação alternativa e ampliada dentre os quais se destacam computadores acessíveis; adequação de ambientes; a adaptação de atividades escolares e de equipamentos de lazer e recreação e o transporte adaptado devem estar disponíveis em vários ambientes da instituição, no entanto, isso nem sempre ocorre, pois são escassos e ficam restritos ao setor de acessibilidade.

7 Segundo Pelosi e Nunes (2009), Tecnologia Assistiva é uma área de conhecimento que tem como objetivo desenvolver recursos e serviços parra atender as necessidades específicas de indivíduos com perdas funcionais decorrentes de deficiências, visando melhorar a qualidade de vida deles.
Embora os documentos analisados informem que os atendimentos especializados estejam assegurados ao acadêmico com deficiência na Instituição, os recursos de tecnologia assistiva ainda são escassos e os que existem estão restritos ao setor de acessibilidade. Registre-se que no relatório desse setor está prevista a aquisição desses recursos e materiais, a fim de distribuí-los para as Unidades.

Aliada à questão da infraestrutura, a atitude dos professores em sala de aula é digna de nota, haja vista que três participantes com deficiência auditiva (Ac. 03, Ac. 07 e Ac. 08) afirmaram que são prejudicados pela falta de caixas de som nas salas de aula e de microfones para os professores, em decorrência do tom de voz baixo de alguns docentes. Diante disso, esses acadêmicos declararam que se sentem invisíveis e excluídos nas salas de aulas, quando não conseguem um lugar para se sentarem à frente, mais próximo do professor.

Constatou-se que o número de profissionais disponíveis na instituição é considerado insuficiente para atender às especificidades de todos os acadêmicos com deficiência, como tem sido destacado pelos diretores das unidades. $\mathrm{Na}$ ocasião da pesquisa havia disponível, para o referido setor, um intérprete de Língua Brasileira de Sinais, dois técnicos de assuntos educacionais, uma psicóloga e um docente que exerce a função de coordenador; nas demais unidades, tanto da capital como do interior do estado, há nove tradutores intérpretes de Língua de Brasileira de Sinais. Esse número de profissionais é ainda insuficiente diante da necessidade de adequações que a instituição requer para se tornar acessível, pois não basta disponibilizar um espaço de atendimento especial em salas de recursos ou em outros setores específicos, sobretudo quando se trata de Instituições multicampi.

Considerando-se, ainda, que uma das reclamações registradas por todos os participantes diz respeito às dificuldades no processo de ensino, no que tange às relações professor-acadêmico, torna-se imprescindível que ocorram mudanças no projeto político pedagógico dos cursos,além de investimentos voltados ao preparo profissional dos professores da educação superior.

Nesse sentido, os participantes declararam que para terem um bom desempenho acadêmico precisam superar os desafios que a vida na universidade lhes impõe, como chama a atenção o acadêmico Ac 3: "nunca vi um professor do curso com métodos diferentes para surdos, que acredita que um intérprete deve acompanhar esses deficientes". Além disso, ele relata que os professores não se preocupam em atender as suas necessidades educacionais e sim em cumprirem o conteúdo proposto para o semestre, conforme atestam estas falas:

Por vezes você é um aluno surdo e não entende muito bem o que o professor está dizendo, a sala é grande e tem muitos alunos, se você pergunta novamente o professor acha que você está conversando, e se você tenta explicar o motivo da sua não compreensão ele manda você sentar lá na frente, eles não ligam e nem buscam te entender (Ac 3). 
Eles esperam que a gente busque todos os meios para compensar nossa deficiência, mas não lembram que a coordenação não nos escuta sobre colocar microfones nas salas para os alunos que tem problema auditivo escutarem melhor, eles esperam que os professores vão atrás disso, não nós (Ac 5).

Esses relatos sugerem que o acadêmico com deficiência tem que superar as suas limitações sem que a ele seja oferecido algum tipo de apoio especial para viabilizar a sua aprendizagem. A responsabilidade de garantir seu aprendizado é exclusivamente dele e de sua família, portanto, o seu êxito ou seu fracasso também são computados na sua conta. O que se observa é que a universidade é palco também de atitudes de negação da deficiência, as quais movimentam as práticas segregacionistas que pretendem instituir padrão de normalidade física e intelectual, contribuindo, sobremaneira, para estigmatizar e discriminar os estudantes que diferem da norma instituída.

Quando não é possível receber apoio institucional, três acadêmicos disseram que solicitam ajuda de seus colegas de turma (Ac 1, Ac 4, Ac 7), como cópia de material contendo os conteúdos transmitidos pelos professores. No entanto, dois acadêmicos (Ac. 03 e 06) pediram ajuda aos professores e foram atendidos, sendo que um deles adequou a metodologia para facilitar a aprendizagem do acadêmico. Observa-se que as condutas diferentes de cada docente revelam que as ações que seguem o princípio da educação inclusiva ainda ficam restritas às iniciativas individuais, requerendo maiores investimentos na preparação dos docentes.

Cinco acadêmicos participantes mencionaram que têm dificuldades de aprendizagem nas aulas e atribuem, como causa delas, a falta de esforço e de interesse nas disciplinas, assumindo para si o ônus desta situação, como é comum encontrar na história educacional das pessoas com deficiência. Se por um lado o fracasso é justificado pela deficiência, por outro lado o êxito resulta da sua capacidade de superação, minimizando a responsabilidade da instituição em oferecer condições melhores de ensino para esses estudantes.

Chamam atenção dos diretores entrevistados as necessidades educacionais do acadêmico surdo, pois eles afirmaram que os docentes e os técnicos administrativos não possuem conhecimento para se comunicarem com eles; esses entrevistados demonstraram, ainda, preocupação com o número insuficiente de Intérpretes de Libras com formação para traduzirem e interpretarem os conhecimentos científicos das diferentes disciplinas do curso. Essa afirmação pode ser exemplificada no relato do D 07: "tivemos um aluno surdo ano passado e tivemos que esperar semanas para o intérprete de outro setor comparecer ao nosso centro e atender nosso chamado, essa dificuldade em arrumar um intérprete é bem problemática para os cursos". Essa preocupação revela a complexidade da situação, pois as universidades públicas federais contratam o tradutor intérprete de Libras em nível médio ${ }^{8}$, e vários deles não realizaram cursos

$8{\text { Consultar artigo } 4^{\circ}}^{\circ}$ da Lei $n^{\circ} 12.319$, de $1^{\circ}$ de setembro de 2010 , que regulamenta a profissão de Tradutor e Intérprete de Libras. que os capacitassem para atuarem nas disciplinas desse nível de ensino (Lacerda \& Gurgel, 2011).

Faz-se urgente que haja cursos de formação de profissionais tanto em nível médio, como em nível superior para atender às especificidades das diferentes áreas do conhecimento. Além disso, o ingresso de estudante surdo em um determinado curso de graduação e pós-graduação exigirá que a universidade forneça a preparação específica para o Tradutor e Intérprete da língua brasileira de sinais, para que ele possa atuar de forma colaborativa com os docentes e outros envolvidos com as disciplinas dos cursos, como por exemplo, os técnicos de laboratórios.

Nesse sentido, a oferta de cursos de formação continuada precisa entrar na agenda da instituição com mais frequência. Além disso, informações sobre as necessidades específicas de estudantes com deficiências precisam ser disponibilizadas nos veículos de comunicação da Universidade. Tudo indica que ainda há muito preconceito em decorrência da falta de informação sobre as deficiências e as necessidades específicas, que são acentuadas nas relações estabelecidas no âmbito institucional. Essa situação coincide com o estudo de Pieczkowsk (2014) e de Cabral (2017).

A existência de um setor de acessibilidade não é suficiente para abarcar a responsabilidade de fazer as mudanças estruturais necessárias para adequação das IES, tanto em nível da sua infraestrutura, do seu currículo e da formação de seus profissionais. Esse setor deve colaborar para produzir conhecimentos específicos que avancem na perspectiva da inclusão, mas não assumir sozinho as mudanças necessárias para transformar a política institucional. Essa transformação só será possível quando se aceitar que o uno é composto pelo diverso.

\section{Considerações Finais}

Esta pesquisa demonstrou que as condições de acessibilidade em uma universidade pública federal ainda carecem de investimentos na infraestrutura, no currículo, no sistema de informação e na formação de profissionais (professores e técnicos administrativos). Embora esses aspectos estejam previstos no Plano de Desenvolvimento Institucional, há muito que investir na mudança de concepções do ensino e aprendizagem, sobretudo quando se apresenta como lócus de vanguarda para assegurar os direitos educacionais dos acadêmicos com deficiência, rompendo com práticas que se pautam na cultura da normalização e homogeneização.

São vários os entraves observados no desenvolvimento deste estudo, dentre os quais se destacam as barreiras impostas pela burocracia institucional, asseguradas por normativas que engessam os currículos dos cursos. Esses aspectos merecem estudos mais adensados, pois se sabe muito pouco sobre como se pode construir um currículo acessível, contemplando a criação de metodologias mais ativas com a participação efetiva do acadêmico com deficiência. 
Existem divergências de informações sobre o público alvo dos atendimentos, a exemplo do caso da presença de um estudante com deficiência intelectual matriculado em unidade da instituição, sem que os setores de matrícula e de acessibilidade tivessem conhecimento; mencione-se também a ausência, nas estatísticas, de estudantes com altas habilidades/superdotação. Outro desafio diz respeito às barreiras atitudinais, que se expressam por meio da indiferença, comiseração, intolerância entre outros comportamentos de professores, técnicos, gestores, colegas de turma na relação com as pessoas que apresentam deficiências.

As atuais políticas que normatizam os programas que visam assegurar a educação inclusiva nas universidades são percebidas, por parte dos diretores das unidades, como um encargo a mais para o professor, que já é onerado pelas exigências da produção de pesquisas, extensões e publicações para manter os níveis de excelência dos cursos. $O$ produtivismo que tem assolado a academia valoriza pouco a atividade docente, ou seja, aquela que envolve diretamente a relação professor - estudante. Nesse sentido, há necessidade de se construírem ações integradas entre o ensino, a pesquisa e a extensão, em que todos possam ser protagonistas da vida acadêmica.

A educação inclusiva é princípio norteador da política institucional e deve estar na base das ações dos seus membros. Nesse sentido, o setor de acessibilidade deve alargar o seu campo de atuação para além dos seus muros, para que ele não ganhe status ambulatorial, referendando a tendência patologizante que acompanha a história da educação de pessoas com deficiência no Brasil.

\section{Referências}

Alcoba, S. A. C. Estranhos no ninho: a inclusão de alunos com deficiência na UNICAMP. 2008. 231f. Tese (Doutorado em Educação) - Universidade Estadual de Campinas, 2008.

Anache, A.A.; Rovetto, S.S.M.; Oliveira, R.A. (2014). Desafios da implantação do atendimento educacional especializado no Ensino Superior. Revista Educação Especial, 27(49), 299-312.

André, M. (2013). O que é um estudo de caso qualitativo em educação? Revista da FAEEBA - Educação e Contemporaneidade, 22(40), 95-103. Recuperado: 04 mar. 2017. Disponível: https://revistas. uneb.br/index.php/faeeba/article/viewFile/753/526

Araujo, J.P.; Schmidt, A. (2006). A inclusão de pessoas com necessidades especiais no trabalho: a visão de empresas e de instituições educacionais especiais na cidade de Curitiba. Revista Brasileira de Educação Especial, 12(2), 241-254. Recuperado: 05 mar. 2017. Disponível: https://dx.doi.org/10.1590/S141365382006000200007

Bisol, C.A.; Valentini, C.B.; Simioni, J.L. (2010). Estudantes Surdos no ensino superior: reflexões sobre a inclusão. Cadernos de Pesquisa, 139 (40), 147-172.
Brasil. Decreto $n^{\circ} 5.296$ de 2 de dezembro de 2004. Regulamenta as Leis nos 10.048 , de 8 de novembro de 2000 , que dá prioridade de atendimento às pessoas que especifica, e 10.098, de 19 de dezembro de 2000, que estabelece normas gerais e critérios básicos para a promoção da acessibilidade das pessoas portadoras de deficiência ou com mobilidade reduzida, e dá outras providências. Diário Oficial da União, Brasília, 3.12.2004.

Brasil (2010). Infraestrutura Social e urbana no Brasil: subsídios para uma agenda de pesquisa e formulação de políticas públicas, livro 6 , v. 2, Brasília.

Brasil (2008). Decreto $n^{\circ} 6.571$, de 17 de setembro de 2008. Dispõe sobre $\mathrm{o}$ atendimento educacional especializado, regulamenta o parágrafo único do art. 60 da Lei $n^{\circ} 9.394$, de 20 de dezembro de 1996, e acrescenta dispositivo ao Decreto no 6.253 , de 13 de novembro de 2007. Diário Oficial da União, Brasília, 18.9.2008.

Brasil (2011). Decreto $\mathrm{n}^{\circ}$ 7.611, de 17 de novembro de 2011 Dispõe sobre a educação especial, o atendimento educacional especializado e dá outras providências. Diário Oficial da União, Brasília, 18 nov.2011.

Brasil (2013). Programa incluir, acessibilidade na educação superior Documento orientador. Brasil: SECADI/SESu.

Brito, J.; Zeppone, R.M.O. (2013). Mapeamento de teses e dissertações sobre a inclusão de pessoas com deficiência no ensino superior no Brasil.In: VIII Encontro da Associação Brasileira de Pesquisadores em Educação Especial. Londrina, PR: UEL. Recuperado: 05 set. 2015. Disponível: http://www.uel.br/eventos/ congressomultidisciplinar/pages/arquivos/anais/2013/AT01-2013/ AT01-010.pdf

Cabral, L.S.A. (2017). Inclusão do público -alvo da educação especial no ensino superior brasileiro: histórico, políticas e práticas. Revista de Educação PUC-Campinas, 22(3) 371-387.

Camargo, E.P. (2012). Saberes docentes para a inclusão do aluno com deficiência visual em aulas de física. São Paulo: Editora UNESP.

Cambruzzi, R.C.S.; Costa, M.P.R.; Denari, F.E. (2013). Acessibilidade de um cadeirante em uma instituição pública do ensino superior: rotas e rotinas, Revista Educação Especial, 46(26), 351-366.

Decreto 5.626, de 22 de dezembro de 2005 (2005, 22 de dezembro). Regulamenta a Lei no 10.436 , de 24 de abril de 2002, que dispõe sobre a Língua Brasileira de Sinais - Libras, e o art. 18 da Lei no 10.098, de 19 de dezembro de 2000. Brasil: Presidência da República. Recuperado: 20 ago. 2016. Disponível: http://www. planalto.gov.br/ccivil_03/_ato2004-2006/2005/decreto/d5626.htm

Decreto 12.711, de 29 de agosto de 2012 (2012, 29 de agosto). Dispõe sobre o ingresso nas universidades federais e nas instituições federais de ensino técnico de nível médio e dá outras providências. Brasília, DF: Presidência da República. Recuperado: 
05 jul. 2017. Disponível: http://www.planalto.gov.br/ccivil_03/_ ato2011-2014/2012/Lei/L12711.htm

Decreto $n^{\circ} 9.034$ de 20 de abril de 2017 (2017, 20 de abril). Altera o Decreto $n^{\circ} 7.824$, de 11 de outubro de 2012, que regulamenta a Lei $\mathrm{n}^{\circ} 12.711$, de 29 de agosto de 2012, que dispõe sobre o ingresso nas universidades federais e nas instituições federais de ensino técnico de nível médio. Brasília, DF: Presidência da República. Recuperado: 05 dez. 2017. Disponível: http://www.planalto.gov.br/ ccivil_03/_ato2015-2018/2017/decreto/D9034.htm

Harvey, L.; Williams, J. (2010). Fifteen years of quality in higher education. Quality in Higher Education, 1 (16), 3-36.

Instituto Nacional de Estudos e Pesquisas Educacionais Anísio Teixeira [Inep] (2014). Sinopses estatísticas da educação superior - graduação: censo da educação superior de 2014. Recuperado: 07 dez. 2017. Disponível: http://portal.inep.gov.br/superiorcensosuperior-sinopse.

Lacerda, C.B.F.; Gurgel, T.M.A. (2011). Perfil de tradutores-intérpretes de Libras (TILS) que atuam no ensino superior no Brasil. Revista Brasileira de Educação Especial, 3 (17), 481-496.

Lei $n^{\circ} 12.319$, de $1^{\circ}$ de setembro de 2010 (2010, 1 de setembro). Regulamenta a profissão de Tradutor e Intérprete da Língua Brasileira de Sinais - LIBRAS. Brasília, DF: Presidência da República.

Lei $n^{\circ}$ 13.146, de 6 de julho de 2015 (2015, 6 de julho). Institui a Lei Brasileira de Inclusão da Pessoa com Deficiência (Estatuto da Pessoa com Deficiência). Brasília, DF: Diário Oficial da União.

Lima, P.E.A. (2012). O acesso e permanência de indivíduos surdos no ensino superior. Dissertação de Mestrado, Pontifícia Universidade Católica de São Paulo, São Paulo, SP.

Marques, L.S.; Gomes, C. (2014). Concordâncias/discordâncias acerca do processo inclusivo no ensino superior: um estudo exploratório. Revista Educação Especial, 49 (27), 313-325.

Moreira, H.F.; Michels, L.R.; Colossi, N. (2006) Inclusão educacional para pessoas portadoras de deficiência: um compromisso com o ensino superior, Revista Escritos sobre Educação, 1(5), 19-25.

Moreira, L. C.; Bolsanello, M. A.; Seger, R. G. (2011). Ingresso e permanência na Universiade: alunos com deficiência em foco. Educar em Revista n. 41, p.125-143, 2011.

Nogueira, F.L.B.M. (2012). Políticas institucionais e ações inclusivas nas universidades: análise das condições de acesso para discentes surdos. Mestrado em Administração de Empresas, Universidade de Fortaleza, Fortaleza, CE.

Pereira, M.M. (2006). A inclusão de alunos com necessidades educativas especiais no ensino superior, UNIrevista,2(1), s.p.
Pereira, F.J.R.; Santos, S.R.; Silva, C.C. (2011). Política de formação inclusiva: percepção de gestores sobre processo de mudanças em instituições de ensino superior. Revista Brasileira de Enfermagem, 4 (64), 711-716.

Pelosi, M.B.; Nunes, L.R.O.P. (2009). Caracterização dos professores itinerantes, suas ações na área de tecnologia assistiva e seu papel como agente de inclusão escolar. Revista Brasileira de Educação Especial, 15(1), 141-154. Recuperado: 05 jan. 2017. Disponível: https://dx.doi.org/10.1590/S1413-65382009000100010.

Pieczkowski, T.M.Z. (2014). Inclusão de estudantes com deficiência na educação superior: efeitos na docência universitária. Tese de Doutorado em Educação, Programa de Pós-Graduação em Educação, Universidade Federal de Santa Maria, Santa Maria, RS.

Reis, N.M.M. (2010). Política de inclusão escolar de pessoas com necessidades educacionais especiais no ensino superior e as universidades federais mineiras, Dissertação de Mestrado, Faculdade de Educação, UFMG, Belo Horizonte, MG.

Universidade Federal de São Paulo. (2016) Relatório Executivo: Seminário Local de Acessibilidade e Inclusão na Unifesp. São Paulo, SP. Pró-Reitoria de Assuntos Estudantis - Prae. http://www. unifesp.br/images/DCl/RelatorioResumidoUnifespParaTod@s.

Rocha, T.B.; Miranda, G.T. (2009). Acesso e permanência do aluno com deficiência na instituição de ensino superior. Revista de Educação Especial, 22 (34), 197-212. Recuperado: 05 abr. 2016. Disponível: https://periodicos.ufsm.br/educacaoespecial/issue/view/13.

Santana, L.L.S. (2016) Acesso e permanência na educação superior - estratégias e ações da divisão de acessibilidade e ações afirmativas/DIAF na UFMS. Dissertação de Mestrado, Programa de Pós-Graduação em Educação,Universidade Federal de Mato Grosso do Sul, Campo grande, MS.

Sá, E.D.; Campos, I.M.; Silva; M.B.C. (2007). Atendimento Educacional Especializado: Deficiência visual. Brasília, DF: SEESP / SEED / MEC.

Siqueira, M.G.S.; Aquillera, F. (2015). Modelos e diretrizes para uma educação inclusiva: revisão de literatura,Revista Educação Especial,28(52). 281-294.

Siqueira, I.M.; Santana, C.S. (2010). Propostas de acessibilidade para a inclusão de pessoas com deficiências no ensino superior. Revista Brasileira de Educação Especial, 1(16), 27-136.

Sistemas Conselhos Federal de Fonoaudiologia e de Regionais de Fonoaudiologia (2013). Manual de procedimentos em audiometria tonal limiar, logoaudiometria e medidas de imitância acústica. Brasília, DF.

Shogren, K.A.; Snell, M.E.; Spreat, S.; Tassé, J.M.; Thompson, J.R.; Verdugo-Alonso, M.A.; Wehmeyer, M.L.; Yager, M.H. (2010) 
Intelectual Disability: definition, classification and systems of support. Washington (DC): AAIDD.
License information: This is an open-access article distributed under the terms of the Creative Commons Attribution License (type CC$\mathrm{BY}$ ), which permits unrestricted use,distribution and reproduction in any medium, provided the original article is properly cited.

Recebido em: 16 de dezembro de 2017

Aprovado em: 16 de fevereiro de 2018

\section{Sobre as autoras}

Alexandra Ayach Anache (alexandra.anache@gmail.com)

Professora Titular do Centro de Ciências Humanas e Sociais da Universidade Federal de Mato Grosso do Sul. Campo Grande - MS.

https://orcid.org/0000-0002-7937-4448

Lysa Duarte Cavalcante (gaticha9_6@yahoo.com.br)

Acadêmica do curso de Pedagogia Centro de Ciências Humanas e Sociais da Universidade Federal de Mato Grosso do Sul. Campo Grande - MS. https://orcid.org/0000-0002-9363-6897

Este trabalho está vinculado à pesquisa "Acessibilidade no Ensino Superior" UNESP, OBEDUC/CAPES - Proc. 23038.002628/2013-41. 